Greer, S. (1960). J. gen. Microbiol. 22, 618-634

\title{
Studies on Ultraviolet Irradiation of Escherichia coli Containing 5-Bromouracil in its DNA
}

\author{
By S. GREER \\ Department of Biochemistry, Columbia University, College of Physicians and \\ Surgeons, New York, U.S.A.
}

SUMMARY: Thymine-requiring Escherichia coli $15, \mathrm{t}^{-}$and $E$. coli $\mathrm{B}, \mathrm{t}^{-}$which contained 5-bromouracil in their deoxyribonucleic acid in place of thymine showed a marked increase in sensitivity to ultraviolet (u.v.) radiation. The effect was proportional to the extent of incorporation of 5-bromouracil under defined growth conditions and for a given medium. This increase in sensitivity to u.v. was not hereditary. A maximum u.v. dose-increase effect on survival of 3.5 was obtained ; there was as high as a $\mathbf{2 0 , 0 0 0}$-fold decrease in the number of survivors as compared to irradiated bacteria grown in absence of the analogue. This effect was not obtained with bacteria grown before irradiation in 2-thiothymine (an inhibitor not incorporated into DNA), nor was there an increase in u.v. sensitivity in organisms grown under conditions of thymine starvation or of 5-flurouracil inhibition. Furthermore, bacteria which did not require thymine and did not incorporate 5-bromouracil did not show this sensitization effect. The increase in u.v. sensitivity caused by 5-bromouracil was annulled by thymine. 5-Iodouracil caused a lower increase in u.v.-sensitization. The extent of photo-reactivation was not as great in irradiated bacteria which had been grown in 5-bromouracil as in bacteria containing no analogue in their DNA. A u.v.-resistant mutant of $E$. coli $15, \mathrm{t}^{-}$was isolated and found to be affected by 5 -bromouracil in a manner similar to the slightly more u.v.-sensitive parent strain. Incorporation of 5-bromouracil did not result in a dose-increase effect on u.v.-induced mutagenesis at the thymine-dependent locus of $E$. coli $15, \mathrm{t}^{-}$. Bacteria containing 5-bromouracil were similarly hypersensitive to heat but showed no increased sensitivity to $\mathrm{H}_{2} \mathrm{O}_{2}$ and several nitrogen mustards.

After it was found that 5-bromouracil could replace $48 \%$ of the thymine in the deoxyribonucleic acid of a thymine-dependent mutant of Escherichia coli, strain 15 (Zamenhof \& Griboff, 1954), studies were made to determine the biological effects of this incorporation. While studying the mutagenic effects of this compound in several organisms (see Zamenhof, De Giovanni \& Greer, 1958), it was found that bacteria containing 5 -bromouracil were killed more easily by u.v. radiation than were bacteria containing thymine.

Most of the physical and chemical agents that have recently been investigated affect sensitivity to u.v. radiation in the opposite manner; that is, they protect the organisms from irradiation. It was apparent that studies of this system might contribute to the comprehension of u.v.-induced lethality and mutagenesis, as well as increase the understanding of properties of unnatural DNA, thus complementing the chemical studies in progress in this laboratory on the correlation between the change in structure and the change in function of nucleic acids (Zamenhof \& Griboff, 1954; Zamenhof, De Giovanni \& Rich, 1956; Zamenhof, 1956). A summary of these radiation studies was presented previously (Greer \& Zamenhof, 1957). 


\section{METHODS}

Organisms. The organism primarily used in these studies was Escherichia coli, strain 15, thymine-dependent $\left(\mathrm{t}^{-}\right)$described previously as strain I (Zamenhof \& Griboff, 1954). Other derivatives of this strain were used: $E$. coli 15, thymine ${ }^{+}\left(t^{+}\right)$a back mutant of $15, t^{-} ; E$. coli $15, t^{-} / 5 B U$, resistant to $50 \mu \mathrm{g} 5$-bromouracil $/ \mathrm{ml}$. in supplemented minimal medium; the original wild-type $\boldsymbol{E}$. coli 15 . In several experiments, $E$. coli, strain B, and a thymine-requiring derivative isolated by $\mathrm{Dr} \mathrm{S}$. Brenner, $E$. coli $\mathrm{B}, \mathrm{t}^{-}$(B3) were used.

Media. Before irradiation $10^{5}$ bacteria $/ \mathrm{ml}$. were grown at $37^{\circ}$ for $48 \mathrm{hr}$. in appropriately supplemented Gray and Tatum's medium as modified by Ryan \& Schneider (1948), which is referred to as minimal medium throughout this paper. The limiting growth factor was $0.1 \%(w / v)$ glucose. In several experiments an enriched medium containing nutrient broth, proteose peptone, and glucose was used (Zamenhof, De Giovanni \& Rich, 1956). In this latter medium the bacteria were irradiated after growth for $24 \mathrm{hr}$. at $37^{\circ}$. The final concentration of viable bacteria in minimal and enriched medium containing no analogue was $5 \times 10^{8}$ and $2 \times 10^{9}$ bacteria/ml., respectively.

Irradiation. After washing the bacteria in $0.8 \%(\mathrm{w} / \mathrm{v})$ saline, the organisms were irradiated in subdued visible light with a 8 W General Electric Germicidal Lamp G-8, T-5 having its maximum output at $2537 \AA$., in $10 \mathrm{ml}$. suspensions containing $5 \times 10^{7}$ bacteria $/ \mathrm{ml}$. in saline in a rotating and vibrating Petri dish at a dose rate of $6.8 \mathrm{ergs} / \mathrm{sec} . / \mathrm{mm}^{2}$. Before irradiation, all samples were adjusted to the same bacterial turbidity.

Determination of survival and mutagenesis. After irradiation the organisms were diluted in saline and plated in or on Difco nutrient agar or minimal agar (1.5\%) supplemented with $2 \mu \mathrm{g}$. thymine $/ \mathrm{ml}$. and incubated in the dark at $37^{\circ}$. The same number of survivors was obtained on supplemented minimal agar as on nutrient agar; furthermore, the same viability was obtained with pour-plates as on plates on which the irradiated bacteria were spread. For the analysis of u.v.-induced thymine-independent mutants, Escherichia coli 15, twas grown in enriched medium containing either 0 or $100 \mu \mathrm{g}$. 5-bromouracil/ ml. It was necessary to irradiate many $10 \mathrm{ml}$. samples containing $2 \times 10^{8} \mathrm{bac}$ teria/ml. because of the extensive u.v.-induced mortality that occurred when organisms were grown in 5-bromouracil before irradiation. Thirty ml. minimal agar were added to each plate containing the irradiated suspension. There was no suppression of mutants by the parental population under these conditions. After 4 days of incubation at $37^{\circ}$, the frequency of thymine-independent mutants was determined.

Photo-reactivation studies. To determine the extent of photo-reactivation, irradiated bacteria were spread on the surfaces of nutrient agar plates and immediately placed under four General Electric $40 \mathrm{~W}$. fluorescent lamp bulbs at a dose of $1000 \mathrm{ft}$.-candles for a period of $4 \mathrm{hr}$. at $37^{\circ}$ and then incubated in the dark with the control plates for an additional $20 \mathrm{hr}$. Although this method is not as effective as a method in which the bacteria are irradiated with visible 
light in a liquid suspension in a test tube, reproducible results were obtained in many repeated experiments.

Attempts to isolate a radiation resistant mutant. The technique of Witkin (1947) as applied to Escherichia coli, strain B, was used with $E$. coli $15, t^{-}$. In spite of intensive investigation, a mutant that was more resistant than the one isolated, $E$. coli $15, t-R(5 \times$ resistant) could not be found. Isolation of $E$. coli $B, t-/ R$ was not achieved. This may be related to the fact that $B, t^{-}$is initially approximately 5 times more radiation resistant than strain $B$, in terms of survival. In addition, $E$. coli $\mathrm{B}, \mathrm{t}^{-}$is more resistant to inhibition by crystal violet, safranin, and hydrogen peroxide than strain $B$; its resistance to these agents is similar to the resistance of $E$. coli $B / R$. It should be noted that the isolate of $E$. coli $\mathrm{B}$ used in these studies is not identical to the parental strain from which $E$. coli $B, t$ - was derived.

Incorporation analysis. The extent of incorporation of 5-bromouracil into bacterial DNA was measured by the method of Zamenhof \& Griboff (1954) modified by growing the bacteria in 21 . supplemented minimal medium.

Inhibition with 2-thiothymine, 5-fluorouracil and thymine starvation. The u.v. sensitivity of Escherichia coli $15, \mathrm{t}^{-}$was determined after growth in 2-thiothymine, an analogue that is similar in inhibitory properties to 5-bromouracil, causes elongation of bacteria in a similar manner but is not incorporated into DNA. The bacteria were grown under conditions in which 2-thiothymine was equal in concentration and extent of inhibition of the rate of growth and final viable count as obtained with 5 -bromouracil. Similarly, the sensitivity to u.v. radiation of $E$. coli $\mathrm{B}$ and $E$. coli $\mathrm{B}, \mathrm{u}^{-}$(uracil dependent) was determined after these organisms were subjected to the conditions of 5 -fluorouracil inhibition as described by Cohen et al. (1958). In addition, $E$. coli 15, t- was grown under conditions of thymine starvation described by Cohen $\&$ Barner (1954). The bacteria were irradiated after various periods of starvation. Appropriate control cultures grown in media containing neither glucose nor thymine, or both glucose and thymine were also irradiated.

\section{RESULTS}

Table 1 summarizes the effects of growth, before irradiation in media containing 5-bromouracil or 2-thiothymine, on survival of Escherichia coli 15, $t^{-}$following u.v. irradiation. Although 2-thiothymine was used in conditions in which it is essentially equal in concentration and extent of inhibition of the rate of growth and final concentration of viable bacteria as obtained with 5-bromouracil, 2-thiothymine has no effect on irradiation sensitivity in enriched medium and only a slight effect on sensitivity to irradiation in minimal medium. Consistent with these results are the findings of Zamenhof, Reiner, De Giovanni \& Rich (1956) that 2-thiothymine was not incorporated into DNA while 5-bromouracil was to the extent of $48 \%$ in enriched medium (Zamenhof \& Griboff, 1954) and $42 \%$ in minimal medium as the present studies will show. Analogue-inhibition alone does not account for the increase in sensitivity to u.v. radiation; in fact a lower sensitization effect was obtained when bacteria were grown in enriched medium containing $1000 \mu \mathrm{g} .5$-bromo-uracil $/ \mathrm{ml}$. 
Table 1. Effect of pretreatment with 2-thiothymine or 5-bromouracil on survival following u.v. irradiation of Escherichia coli 15, $t^{-}$

\begin{tabular}{|c|c|c|c|c|c|c|c|c|c|c|c|c|}
\hline Medium & & & Enrich & d medium & & & & Minir & mediu & $+2 \mu \mathrm{g}$. & */ml. & \\
\hline Analogue & & 2-Th & hymine & & $5 \mathrm{BU}$ & & & & hiothyr & & & $5 \mathrm{BU}$ \\
\hline Concn. of analogue $(\mu \mathrm{g} . / \mathrm{ml})$. & $\mathbf{0}$ & 100 & 800 & 1000 & 100 & 1000 & $\mathbf{0}$ & 10 & 30 & 100 & 300 & 10 \\
\hline$\%$ viability $\dagger$ & 100 & 100 & 72 & 42 & 46 & 13 & 100 & 100 & 100 & 81 & 8.7 & 52 \\
\hline Generation time in min. & 20 & 20 & 21 & 22 & 20 & 22 & 60 & 60 & 60 & 109 & 140 & 105 \\
\hline$\% \mathrm{~S}^{*}$ at dose $410 \mathrm{ergs} / \mathrm{mm} .^{2}$ & $\mathbf{3 \cdot 3}$ & $2 \cdot 8$ & $3 \cdot 9$ & $4 \cdot 0$ & 0.051 & $\mathbf{3 \cdot 0}$ & $7 \cdot 1$ & $5 \cdot 8$ & $4 \cdot 0$ & 1.5 & $1 \cdot 2$ & 0.12 \\
\hline Sensitization factor $\ddagger$ & - & 1.2 & 0.85 & 0.82 & 65 & 1.1 & - & $1 \cdot 2$ & 1.8 & 4.7 & 5.9 & 59 \\
\hline$\% \mathrm{~S}$ at dose of $680 \mathrm{ergs} / \mathrm{mm}^{2}$ & - & 一 & - & - & - & 一 & 0.32 & 0.26 & $0 \cdot 14$ & 0.08 & 0.04 & 0.002 \\
\hline Sensitization factor & - & - & - & - & - & - & - & 1.2 & $2 \cdot 3$ & 4.0 & 8.0 & 1230 \\
\hline
\end{tabular}

* S, survival; $\mathrm{T}$, thymine; $5 \mathrm{BU}, 5$-bromouracil.

$\dagger \%$ viability $=$ concentration of viable organisms in cultures grown in analogue $\times 100 /$ concentration of viable organisms in cultures grown in absence of the analogue. ( $5 \times 10^{8}$ bacteria $/ \mathrm{ml}$. in minimal medium; $2 \times 10^{9} \mathrm{bacteria} / \mathrm{ml}$. in enriched medium.)

$\ddagger$ Sensitization factor $=\% \mathrm{~S}$ of irradiated control $/ \% \mathrm{~S}$ of irradiated culture previously grown in analogue. 
than when grown in enriched medium containing $100 \mu \mathrm{g}$. 5-bromo-uracil $/ \mathrm{ml}$. Zamenhof, De Giovanni \& Rich (1956) showed that there was no incorporation at the higher concentration. The secondary inhibition which is not due to incorporation alone but to a more general inhibition of the organism is apparently detrimental to incorporation. One further example of the uniqueness of the 5-bromouracil effect on u.v. sensitization is the finding that under conditions of thymine starvation, where a 130-fold decrease in viability due to thymineless death occurred, there was no increase in u.v. sensitization. This was determined for cultures of various degrees in thymine starvation which were tested at many doses of u.v. radiation. Similarly, it was found that under conditions of 5-fluorouracil inhibition n Escherichia coli $\mathrm{B}$ and $E$. coli $\mathrm{B}, \mathrm{u}^{-}$ there was no increase in $u . v$. sensitization, with the exception of a slight effect
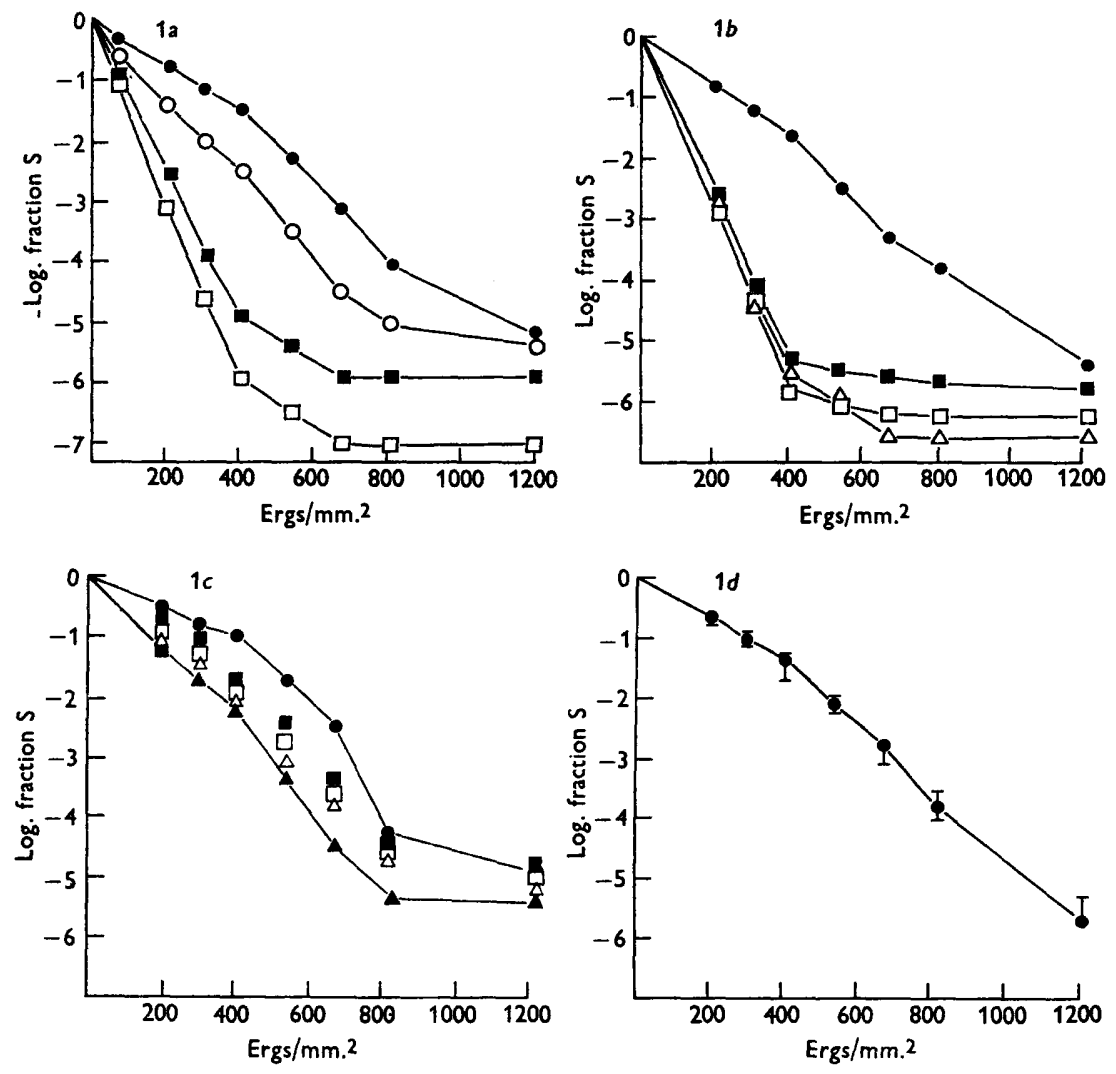

Fig. 1 $a$-d. Effects of pretreatment with 5-bromouracil on survival, following u.v. irradiation in four mutants of Escherichia coli, strain 15. Graph $1 a: E$. coli, strain 15, t(strain I). No growth was obtained in medium containing $50 \mu \mathrm{g}$. 5-bromouracil $/ \mathrm{ml}$. Graph $1 b: E$. coli, strain 15, t-/5-bromouracil, resistant to $50 \mu \mathrm{g}$. 5-bromouracil $/ \mathrm{ml}$. No growth was obtained in medium containing $100 \mu \mathrm{g}$. 5-bromouracil/ml. Graph $1 c$ : $E$. coli, strain $15, \mathrm{t}^{+}$, a back mutant of $15, \mathrm{t}^{-}$. Graph $1 d: E$. coli, strain 15 , thymine independent wild-type. Pre-irradiation growth medium was minimal medium $+1 \mu \mathrm{g}$. thymine $/ \mathrm{ml}$. with 0 , $0 \mu \mathrm{g}$. 5BU $/ \mathrm{ml}$.; $\bigcirc, 1 \mu \mathrm{g} .5 \mathrm{BU} / \mathrm{ml}$.; $\mathbf{a}, 5 \mu \mathrm{g} .5 \mathrm{BU} / \mathrm{ml}$; $\square, 20 \mu \mathrm{g}$. $5 \mathrm{BU} / \mathrm{ml}$.; $\Delta, 50 \mu \mathrm{g} .5 \mathrm{BU} / \mathrm{ml}_{\text {. }} 4,500 \mu \mathrm{g} .5 \mathrm{BU} / \mathrm{ml}$.; I, 5, 20, and $500 \mu \mathrm{g} .5 \mathrm{BU} / \mathrm{ml}$. 
(maximum of seven-fold in terms of survivors) in strain $B, u^{-}$in the absence of uracil.

The effects of growth of four derivatives of Escherichia coli, strain 15, in media containing 5-bromouracil on survival following subsequent u.v.irradiation are shown in Fig. $1 a-d$. The survivals are expressed as the log. proportion of the initial number of viable organisms. Even with $1 \mu \mathrm{g}$. of 5 -bromouracil $/ \mathrm{ml}$. a relatively constant dose-increase effect of 1.5 was obtained. That is, one would have to irradiate the bacteria grown in the absence of 5-bromouracil at a 1.5 higher dose to achieve the survival obtained when bacteria which had incorporated 5-bromouracil were irradiated. The dose-increase effect is a more precise description of the increased sensitivity since the magnitude of the differences in terms of survivors is dose-dependent. At $20 \mu \mathrm{g}$. 5-bromouracil $/ \mathrm{ml}$. a u.v.-dose increase ratio as high as 3.6 and not less than 3.0 was obtained. The mutant $E$. coli $15, \mathrm{t}-/ 5 \mathrm{BU}$ (Fig. $1 b$ ) showed a similar sensitization effect to that obtained with its parent strain $E$. coli 15, t-, although the rate of growth of the resistant strain was unaffected by $5 \mu \mathrm{g}$. 5-bromouracil/ml. and only slightly inhibited by $20 \mu \mathrm{g} / \mathrm{ml}$; $E$. coli 15 wildtype, which incorporates only $7 \cdot 5 \% 5$-bromouracil in enriched medium (Zamenhof, Rich \& De Giovanni, 1958) showed no sensitization effect at $500 \mu \mathrm{g} . / \mathrm{ml}$. in the present conditions (Fig. 1d). On the other hand, E. coli 15, $\mathrm{t}^{+}($Fig. 1c), which resembles the original parent in that it does not require thymine for growth, showed a significant u.v.-sensitization effect. Zamenhof, Rich \& De Giovanni (1958) showed that $E$. coli $15, t^{+}$incorporates twice as much 5bromouracil as a wild-type strain. The present studies indicated that the growth rate of this back mutant was inhibited by 5 -bromouracil in minimal medium with the concentrations used, while the original parental strain 15 was not inhibited. These findings may indicate that this strain has a pathway for thymidylic acid synthesis which differs from that in the wild type.

The incorporation of 5-bromouracil into Escherichia coli $15, \mathrm{t}^{-}$was investigated under the conditions that were used to grow the bacteria before irradiation for the experiments summarized in Fig. $1 a$. The incorporation obtained with $0,1,5$ and $20 \mu$ g. 5 -bromouracil/ml. was found to be $0,14,35$ and $42 \%$ respectively, with a corresponding u.v.-dose increase ratio of $1,1.5,2.9$ and $3 \cdot 2$, giving results in a linear relationship between degree of incorporation and the u.v.-dose increase ratio.

Irradiation experiments with Escherichia coli, strain $\mathrm{B}, \mathrm{t}^{-}$and $\mathrm{B}$, gave similar results to those obtained with $E$. coli $15, \mathrm{t}^{-}$and $\mathrm{E}$. coli 15 as shown in Fig. $2 a, b$. The viability of $E$. coli $\mathrm{B}$ grown in 500, 1000 and $2000 \mu \mathrm{g}$. of 5bromouracil/ml. was 100,60 and $50 \%$ respectively; the inhibition of growth rate followed a similar pattern; nevertheless, there was very little u.v. sensitization in the thymine-independent culture, while a marked effect was obtained with $E$. coli $\mathrm{B}, \mathrm{t}^{-}$with 1,5 and $50 \mu \mathrm{g}$. 5 -bromouracil $/ \mathrm{ml}$. These findings are consistent with the studies of Zamenhof, Rich \& De Giovanni (1958), who found that $E$. coli $\mathrm{B}, \mathrm{t}-$ incorporated $48 \% 5$-bromouracil in place of thymine when grown in a concentration of $100 \mu \mathrm{g} . / \mathrm{ml}$. in enriched medium, while $E$. coli B did not incorporate more than $4 \%$ when grown in high 
concentrations of 5-bromouracil in enriched medium. In enriched medium, strain B shows a pattern similar to that shown in Fig. 2b. A maximum 15-fold decrease in survival was obtained with $1000 \mu \mathrm{g}$. 5-bromouracil/ml., while at 100 and $2000 \mu \mathrm{g} . / \mathrm{ml}$. there was no sensitization.

Escherichia coli 15, $\mathrm{t}^{-}$containing 5-bromouracil in its DNA began to lose its hypersensitivity to u.v. radiation at a rapid rate as soon as growth in the absence of 5-bromouracil occurred. Loss of sensitivity did not take place when the organisms were suspended in saline for several hours before irradiation. After maximum incorporation, a great loss of sensitization to u.v. radiation was obtained after one division in medium containing thymine and no analogue and a complete loss after less than three divisions; therefore, the sensitization is not hereditary. No deliberate method was used to synchronize cell division. These results also suggest that 5-bromouracil did not select for bacteria in the original inoculum which were hypersensitive to $u . v$. radiation. Consistent with these findings are those of Zamenhof, Rich \& De Giovanni (1959), who showed that 5-bromouracil was replaced by thymine when the bacteria showing maximum incorporation of analogue were grown or even suspended in media containing thymine but no 5-bromouracil.
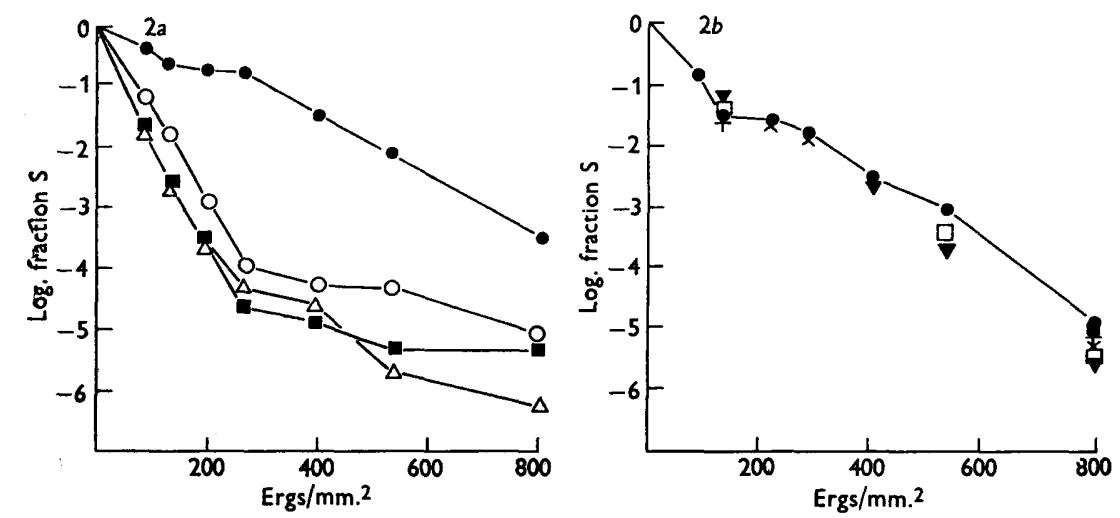

Fig. 2a, b, Effects of pretreatment with 5-bromouracil on survival, following u.v. irradiation of Escherichia coli, strain B, $\mathrm{t}^{-}$, and $E$. coli, strain $\mathrm{B}$ (wild-type). Graph $2 a$ : $E$. coli $\mathrm{B}, \mathrm{t}^{-}$, no growth was obtained at a concentration of $50 \mu \mathrm{g}$. $5 \mathrm{BU} / \mathrm{ml}$. Graph $2 b$ : E. coli B, wild-type. Bacteria were irradiated after growth in minimal medium supplemented with $1 \mu \mathrm{g}$. thymine $/ \mathrm{ml}$. $\bigcirc, 0 \mu \mathrm{g} .5 \mathrm{BU} / \mathrm{ml}$.; $\bigcirc, 1 \mu \mathrm{g} .5 \mathrm{BU} / \mathrm{ml}$.; $\mathbf{\square}, 5 \mu \mathrm{g} . / \mathrm{ml}$.; $\triangle, 20 \mu \mathrm{g} . / \mathrm{ml} . ; \square, 50 \mu \mathrm{g} . / \mathrm{ml} . ; \nabla, 500 \mu \mathrm{g} . / \mathrm{ml}$; $\times, 1000 \mu \mathrm{g} . / \mathrm{ml}$; +, $2000 \mu \mathrm{g} . / \mathrm{ml}$.

The results of several other experiments are compatible with the chemical findings of Zamenhof $(\mathbf{1 9 5 8} b)$. Among these is an experiment in which Escherichia coli $15, \mathrm{t}^{-}$was grown from an inoculum of $10^{6}$ bacteria $/ \mathrm{ml}$. in enriched medium with and without 5-bromouracil, and were irradiated early in the stationary phase (at $7 \mathrm{hr}$. after inoculation) as well as after the bacteria had been in the stationary phase for $17 \mathrm{hr}$. The incorporation at $7 \mathrm{hr}$. was found to be $19 \%$, while at $24 \mathrm{hr}$. it was $48 \%$, an increase with no apparent cell divisions (Zamenhof et al. 1959). In the present work the u.v.-sensitization effect was markedly greater at $24 \mathrm{hr}$. than it was at $7 \mathrm{hr}$. The u.v.-dose increase ratio at $7 \mathrm{hr}$. was $1 \cdot 5$, while at $24 \mathrm{hr}$. it was $2 \cdot 1$. The u.v.-dose increase 


\section{Effects of u.v. on E. coli containing 5-bromouracil}

ratio obtained in minimal medium with lower degrees of incorporation of 5-bromouracil was higher than in enriched medium.

5-Iodouracil which was incorporated into Escherichia coli $15, \mathrm{t}^{-}$(Zamenhof, Reiner, De Giovanni \& Rich, 1956) to a lesser extent than 5-bromouracil ( $14 \%$ compared to $48 \%$ in enriched medium) showed a correspondingly lower sensitization effect in the present work. At a concentration of 10 and $25 \mu \mathrm{g}$./ $\mathrm{ml}$. in supplemented minimal media where there was a corresponding decrease in viability of 34 and $45 \%$, the u.v.-dose increase ratio was 1.6 and 1.7 , respectively (compared to $\mathbf{3 \cdot 0}$ and $\mathbf{3 \cdot 3}$ at the same molarity of 5-bromouracil).

No significant post-irradiation effects of 5-bromouracil were found with cultures of Escherichia coli $15, t^{-}$that were grown in enriched medium containing $100 \mu \mathrm{g}$. 5-bromouracil $/ \mathrm{ml}$. and appropriate control cultures, when irradiated and plated in minimal agar supplemented with $2 \mu \mathrm{g}$. thymine $/ \mathrm{ml}$. and with or without 5-bromouracil. This was determined at several doses of u.v. radiation as well as various non-inhibitory and inhibitory concentrations of 5-bromouracil in the plating medium.

The effect of repeated or alternating cycles of replacement of thymine by 5-bromouracil and subsequent replacement by thymine, etc., on u.v.-sensitization in Escherichia coli 15, $\mathrm{t}^{-}$was tested in the following way. $E$. coli $15, \mathrm{t}^{-}$ was inoculated with $10^{5}$ viable organisms into $5 \mathrm{ml}$. minimal medium $+1 \mu \mathrm{g}$. thymine $+10 \mu \mathrm{g}$. 5-bromouracil $/ \mathrm{ml}$. When the bacteria were in the stationary phase for $20 \mathrm{hr}$, a sample containing $10^{5}$ bacteria was inoculated into minimal medium supplemented with $1 \mu \mathrm{g}$. thymine/ml. and no 5-bromouracil. After this culture was in the stationary phase for $20 \mathrm{hr}$. the bacteria were again inoculated in medium containing 5-bromouracil. This alternating cycle was repeated 15 times; appropriate control cultures were transferred for 30 times in 5-bromouracil media only and another control for 30 repeated transfers in medium containing no 5 -bromouracil. This alternating treatment of $\boldsymbol{E}$. coli $15, t^{-}$did not affect the expected sensitivity to u.v. radiation; that is, bacteria which had been immediately harvested from a culture containing no 5-bromouracil showed no increased sensitivity to u.v. radiation; bacteria that had been irradiated immediately after growth in 5-bromouracil medium showed the usual sensitization effect. Repeated incorporation and replacement of a pyrimidine could increase the frequency of 'wrong' base substitution, giving rise to a DNA with an accumulation of alterations; however, if this does take place, it could not be demonstrated by u.v. sensitization. In addition, this alternating treatment did not affect the frequency of 5-bromouracil-induced mutant-pinpoint colonies.

It is unlikely that the u.v.-sensitization effect is exclusively due to an effect on elongated cells which are obtained when bacteria are grown in the presence of 5-bromouracil. For example, the elongated cells constituted $5 \%$ of the population in a culture that showed a 20,000 -fold increase in u.v. sensitivity in terms of survival. Furthermore, when the elongated cells obtained with Escherichia coli $\mathbf{B}, \mathrm{t}^{-}$after growth in 5-bromouracil were concentrated by differential centrifugation so that they constituted more than $99 \%$ of the population, this bacterial fraction did not show a marked increase in u.v. sensitivity. 
In addition, a culture containing elongated cells resulting from thymine starvation showed no increase in u.v. sensitization.

Figure 3 indicates the effect of increasing concentrations of thymine on the annulment of the u.v.-sensitization effect due to growth in the presence of 5-bromouracil prior to irradiation. This effect is consistent with all the competitive reversal effects that have been observed in the thymine-5-bromouracil system such as reversal of inhibition and incorporation. Similar u.v.-sensitization effects were obtained with similar molar ratios. Significant incorporation occurred when there was a higher molar concentration of thymine than of 5-bromouracil.

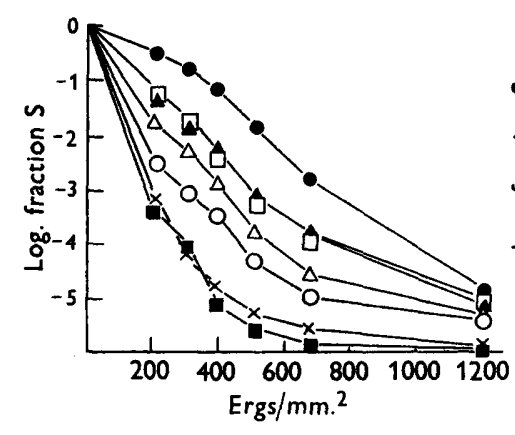

Fig. 3

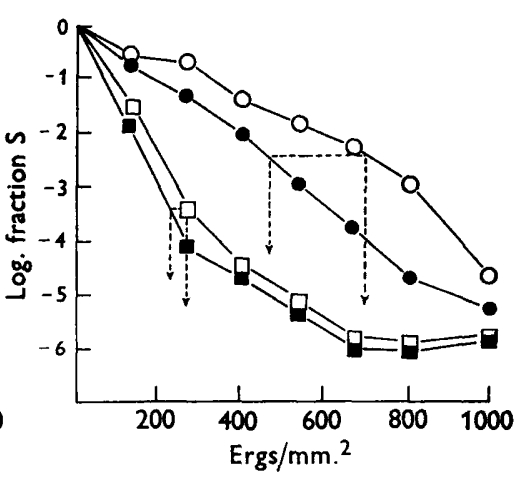

Fig. 4

Fig. 3. Effect of thymine on 5-bromouracil induced u.v.-sensitization in Escherichia coli, $15, \mathrm{t}^{-}$. Before irradiation bacteria were grown in supplemented minimal medium.

$\begin{array}{ccc}\text { Symbol } & \begin{array}{c}\mu \mathrm{M} / \mu \mathrm{M} 5 \mathrm{BU} ; \\ \mathbf{1 5} / 0\end{array} & \begin{array}{c}\text { Quotient of } \\ \text { the molarities }\end{array} \\ \square & \mathbf{5 0} / 50 & - \\ \Delta & 10 / 10 & 1 \cdot 0 \\ \Delta & 40 / 50 & 1 \cdot 0 \\ O & 20 / 50 & 0 \cdot 8 \\ \times & 15 / 75 & 0 \cdot 4 \\ \square & 8 / 40 & 0 \cdot 2 \\ 7 \cdot 9 \mu \mathrm{M} \text { thymine }=1 \mu \mathrm{g} . / \mathrm{ml} . ; 5 \cdot 2 \mu \mathrm{MBU}=1 \mu \mathrm{g} . / \mathrm{ml} .\end{array}$

Fig. 4. Effect of pretreatment with 5-bromouracil on photo-reactivation in Escherichia coli, $15, t^{-}$. Before irradiation bacteria were grown in minimal medium supplemented with $1 \mu \mathrm{g}$. T/ml. O, dark, $0 \mu \mathrm{g}$. 5BU $/ \mathrm{ml}$.; O, light, $0 \mu \mathrm{g} \mathrm{5BU} / \mathrm{ml}$. ; $\square$, dark, $10 \mu \mathrm{g} .5 \mathrm{BU} / \mathrm{ml}$. ; $\square$, light, $10 \mu \mathrm{g}$. 5BU/ml.; dotted line and arrows show how dose-decrease ratio is calculated at a level of $10^{-4}$ survival, intercepting the curve for dark-treated irradiated bacteria containing 5 -bromouracil at a dose of $272 \mathrm{ergs} / \mathrm{mm}^{2}$ and the curve for darktreated irradiated bacteria containing no 5-bromouracil at a dose of $706 \mathrm{ergs} / \mathrm{mm}^{2}$. The dose reduction ratio is then determined for each pair of curves as indicated.

The effect of growth in medium containing 5-bromouracil on photo-reactivaion following u.v. irradiation of Escherichia coli 15, $t^{-}$is shown in Fig. 4. A dose-decrease ratio (Kelner, 1949) of 1.43 was obtained with visible light in bacteria containing no 5-bromouracil, while a dose-decrease ratio of only 1.15 was obtained in the organisms containing 5-bromouracil. A similar effect was obtained with $5 \mu \mathrm{g} . / \mathrm{ml}$. In $E$. coli 15 , wild-type, the same concentra- 
tions of 5-bromouracil had no effect on photo-reactivation after u.v. irradiation. Because photo-reactivation effects diminish as one approaches the level of $10^{-5}$ survival (this was found to occur with irradiated bacteria containing no analogue at doses greater than $900 \mathrm{ergs} / \mathrm{mm}^{2}$ ) one could argue that the lack of photo-reactivation in the 5-bromouracil-treated bacteria could be explained merely by the dose-increase effect; therefore, it is important to consider the dose-decrease effect of photo-reactivating light at a dose where $10^{-4}$ survival was obtained with bacteria incubated in the dark following u.v. irradiation (dotted lines in Fig. 4). The 5-bromouracil-treated cells show a 1.15 dose-decrease effect with visible light while the bacteria grown in absence of 5-bromouracil demonstrate a 1.50 dose-decrease effect. Furthermore, when the bacteria were irradiated at higher doses (1050 ergs $\left./ \mathrm{mm} .{ }^{2}\right)$, where one obtained little difference in survival after u.v. irradiation between bacteria containing $35 \%$ 5-bromouracil and normal bacteria, the latter were photo-reactivated to a significant extent whereas the cells containing 5-bromouracil were not. Results in Fig. 4 do not go beyond a dose of $1000 \mathrm{ergs} / \mathrm{mm} .{ }^{2}$. In the course of these studies it was found that $E$. coli 15 , t-containing 5-bromouracil that have not been $u . v$. irradiated are sensitive to visible light. A 1.5-2.5 decrease in survival occurred when the bacteria were illuminated with $1000 \mathrm{ft}$.-candles for $4 \mathrm{hr}$. This did not occur in the absence of 5-bromouracil and did not occur in $E$. coli 15, wild-type that were grown in the presence of 5-bromouracil. The results in Fig. 4 are corrected for this slight difference; however, it is possible that this effect is synergistic to, or compounded by, u.v.-killing in bacteria containing 5-bromouracil, thereby resulting in an apparent lack of photo-restoration. Contrary to this possibility, however, are the results of experiments with high doses of u.v. radiation (c. $1300 \mathrm{ergs} / \mathrm{mm}^{2}$ ) where there was no photo-restoration in cells containing no 5-bromouracil. Under these conditions, the bacteria containing 5-bromouracil that were incubated in the light had the same survival as those incubated in the dark. However, after heavy doses of u.v. radiation the surviving bacteria may be resistant to killing by visible light just as they are to further u.v.-irradiation.

The effects of 5-bromouracil pretreatment on the radiation sensitivity of a derivative of Escherichia coli $15, \mathrm{t}^{-}(\mathrm{t}-/ \mathbf{R})$ that was slightly but consistently more radiation resistant than the parental strain, 15, $t-$, are shown in Fig. 5. The radiation sensitivity of $E$. coli $15, t-/ R$ was affected by 5 -bromouracil in the same way as the more radiation-sensitive strain. Studies of sensitization by 5-bromouracil incorporation with $E$. coli $B / R$, isolated by Witkin (1947), can be accomplished by the use of folic acid antagonists and may give different results.

The effect of growth in 5-bromouracil before irradiation on the subsequent u.v.-induced mortality and mutation in Escherichia coli 15, $\mathrm{t}^{-}$grown in enriched medium is shown in Fig. 6. The mutation studied was $t^{-}$to $t^{+}$. Under these conditions, $48 \%$ of the thymine was replaced by 5-bromouracil. If 5-bromouracil affected u.v.-induced mutagenesis by a dose-increase response as it appears to affect survival, then the hypothetical curve designated by the dotted line in Fig. 6 would be obtained. For example, irradiating the bacteria 
containing 5-bromouracil at a dose of $360 \mathrm{ergs} / \mathrm{mm} .^{2}$ is equivalent, in terms of survival, to irradiating the bacteria containing no 5 -bromouracil at a dose of $525 \mathrm{ergs} / \mathrm{mm}^{2}{ }^{2}$ The frequency of thymine-independent bacteria per surviving bacterium in cultures containing no 5 -bromouracil at a dose of $525 \mathrm{ergs} / \mathrm{mm}$. $^{2}$ is $5 \times 10^{-7}$; consequently, the theoretical point for the mutation frequency for bacteria containing 5 -bromouracil at a dose of $360 \mathrm{ergs} / \mathrm{mm} .^{2}$ is $5 \times 10^{-7}$ thymine-independent mutants/surviving bacterium. Note that the u.v.sensitization effect was not as great when the bacteria were grown in enriched medium as compared to minimal medium, in spite of higher incorporation of 5-bromouracil in the former instance (compare Fig. 1a). At the u.v.-radia-

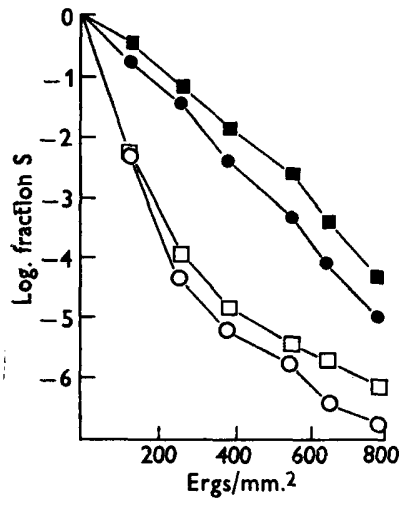

Fig. 5

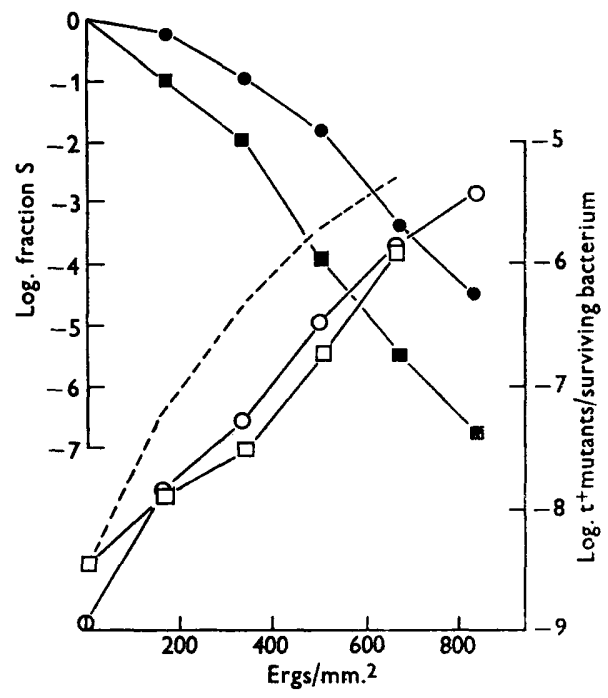

Fig. 6

Fig. 5. Effects of pretreatment with 5-bromouracil on survival, following u.v. irradiation of Escherichia coli, strain $15, \mathrm{t}^{-}$and strain $15, \mathrm{t}^{-} / \mathrm{R}$ (moderately radiation-resistant). Before bacteria were grown in minimal medium supplemented with $1 \mu \mathrm{g}$. $\mathrm{T} / \mathrm{ml}$. $15, \mathrm{t}^{-}, 0 \mu \mathrm{g} .5 \mathrm{BU} / \mathrm{ml}$; $\square, 15, \mathrm{t}^{-} / \mathrm{R}, 0 \mu \mathrm{g} .5 \mathrm{BU} / \mathrm{ml}$. ; O, 15, $\mathrm{t}^{-}, 10 \mu \mathrm{g} .5 \mathrm{BU} / \mathrm{ml} . ; \square, 15$, $\mathrm{t}-/ \mathrm{R}, 10 \mu \mathrm{g} . \mathbf{5 B U} / \mathrm{ml}$.

Fig. 6. Effect of pretreatment with 5-bromouracil in enriched medium on survival and mutation following u.v.-irradiation of $E$. coli, strain 15, $\mathrm{t}^{-} .0,0 \mu \mathrm{g} .5 \mathrm{BU} / \mathrm{ml} .(\mathrm{S})$; $\square$, $100 \mu$ g. 5BU $/ \mathrm{ml}$. (S); $\mathrm{O}, 0 \mu \mathrm{g} .5 \mathrm{BU} / \mathrm{ml}$. (mutation); $\square, 100 \mu \mathrm{g} .5 \mathrm{BU} / \mathrm{ml}$. (mutation); dotted line: hypothetical curve expected if 5 -bromouracil had the same dose-increase effect on the frequency of u.v.-induced thymine-independent mutants/surviving bacterium, that it has on survival.

tion doses of 170,340 and $510 \mathrm{ergs} / \mathrm{mm}^{2}{ }^{2}$, there was an absolute increase in the number of mutants in control cultures grown in absence of the analogue. Furthermore, the thymine-independent mutant had the same sensitivity to u.v. radiation as $E$. coli $15, \mathrm{t}^{-}$when the bacteria were grown in supplemented minimal medium (see Fig. 1 $a, b, d$ ); this was also demonstrated in enriched medium. Therefore, it is likely that the thymine-independent mutants are induced by u.v. radiation and are not selected by u.v. radiation. In irradiated 


\section{Effects of u.v. on E. coli containing 5-bromouracil}

cultures grown in the presence of 5-bromouracil an absolute increase in the number of mutants was not obtained with increasing dose, although there is an increase in the frequency of u.v.-induced mutants per surviving bacterium. Thymine-independent mutants in the cultures grown in 5-bromouracil which are present in the stationary phase at $7 \mathrm{hr}$. would have a selective advantage on u.v. irradiation providing that, following mutation, such bacteria ceased to incorporate 5-bromouracil in the manner of the thymine-dependent parental strain. Because of the low rate of mutation, these mutants more likely appear late in the growth of the culture. There would be a greater selective advantage if such mutants were more similar to wild-type than the back mutant $15, \mathrm{t}^{+}$ (see Fig. 1 $a, c, d$ ). Several mutants from these unirradiated cultures were tested and were found to be similar to $15, t^{+}$. All these considerations suggest the possibility that the theoretical curve should be even higher than shown in Fig. 6.

The thymine-independent mutants may be considered to be 'zero point' mutants (Demerec \& Latarjet, 1946) since they were obtained without any deliberate intermediate cultivation; however, contrary to this view, it must be noted that no thymine-independent mutants were obtained when bacteria that had previously grown in supplemented minimal medium rather than enriched medium were irradiated. Although the bacteria were washed twice after growth in enriched medium, there could have been residual material remaining that would have allowed expression of the mutation. Furthermore, no 'zero point' streptomycin-resistant mutants were obtained when streptomycin-sensitive organisms were irradiated regardless of the pre-irradiation growth medium. In several experiments, bacteria that had grown in supplemented minimal medium containing 5-bromouracil were irradiated and grown for varying periods of time in nutrient broth supplemented with $2 \mu \mathrm{g}$. thymine $/ \mathrm{ml}$., were then washed in saline and plated on minimal agar and thymine supplemented minimal agar containing $100 \mu \mathrm{g}$. streptomycin $/ \mathrm{ml}$. In other experiments the bacteria went through several divisions in minimal agar plates supplemented with thymine before streptomycin was added to the plates in a technique adapted from Newcombe (1952) to determine the frequency of u.v.-induced streptomycin-resistant mutants. In several other experiments, the irradiated bacteria were plated on minimal agar plates containing various concentrations of nutrient broth enrichment as well as various concentrations of thymine to determine the frequency of thymine-independent mutants. The results of all these three series of experiments to determine the effect of 5-bromouracil on the frequency of end-point mutants were ambiguous, although there was a general agreement of the data with the findings shown in Fig. 6, namely no dose-increase effect by 5-bromouracil on mutation.

Physical studies have, thus far, shown no difference between the integrity of DNA containing 5-bromouracil as compared to normal DNA when measured by viscosity changes. DNA of Escherichia coli $15, t^{-}$containing $33 \% 5$-bromouracil in place of thymine was irradiated for several hours at a high intensity $\left(2 \times 10^{5} \mathrm{ergs} / \mathrm{mm}^{2}\right)$ and then heated at $76^{\circ}$ for $1 \mathrm{hr}$. and was found to possess the same viscosity as normal DNA irradiated in the same conditions. It should 
be noted that the measurement of viscosity may not be a sensitive tool to study such alterations. In collaboration with Miss Grace Leidy, E. Hahn and Dr H. Alexander, experiments were pursued (as part of other studies) on the incorporation of 5-bromouracil into the DNA of Haemophilus influenzae. It was considered that studies of the inactivation by u.v.-radiation of the biological activity of DNA containing 5-bromouracil would be of importance in further demonstrating that the genetic material of the bacteria contains 5-bromouracil. In such a system, the increase in u.v.-sensitivity could be demonstrated with specific genetic markers. Inactivation of such markers may be more likely than the subtle modification of a gene for thymine dependence. Although various conditions were used, such as employing folic acid antagonists, and high concentrations of the analogue, no 5-bromouracil (less than $0.5 \%$ ) could be detected in the DNA of $\boldsymbol{H}$. influenzae. Nevertheless, the effect of u.v. radiation on the Transforming Activity of DNA extracted from bacteria that had grown in the presence of 5-bromouracil was investigated since even a very low degree of incorporation could have a substantial biological effect. The u.v. inactivation of the transforming activity (ability to confer streptomycin resistance on recipient bacteria) was exactly the same as that of the Transforming Activity of DNA obtained from bacteria that had not grown in 5-bromouracil.

As part of a study on the effect of heat on depurination of DNA in mutagenic conditions at physiological pH (see Greer \& Zamenhof, 1959), Escherichia coli $15, \mathrm{t}-$ containing $30 \% 5$-bromouracil in place of thymine was subjected to heating at $60^{\circ}$. These bacteria were found to be 1500 times more sensitive, in terms of survival, to heating at $60^{\circ}$ at a level of $10^{-6}$ survival (at $2 \frac{1}{2} \mathrm{hr}$.) in nutrient broth containing $\mathbf{5 0} \%$ sucrose, than are bacteria containing no analogue. Less than a tenfold difference was obtained when the bacteria were heated in saline where $10^{-6}$ survival is achieved after only $30 \mathrm{~min}$. In the protective nutrient broth-sucrose medium where death may be due more to nuclear inactivation than in other media, the greatest difference between survival of cultures containing 5-bromouracil and normal bacteria was obtained after long exposures to heat under conditions in which mutagenesis by heat in bacteria containing no analogue has been demonstrated by Zamenhof \& Greer (1958). Hypersensitivity to heat does not occur in this strain if the bacteria are grown in 10 or $100 \mu \mathrm{g}$. of 2-thiothymine/ml. or if $E$. coli 15 is grown in the presence of 5 -bromouracil.

Utilizing various concentrations and times of exposure in saline or sucrose at various levels of survival $\left(10^{-2}\right.$ to $\left.10^{-7}\right), \mathrm{H}_{2} \mathrm{O}_{2}$, crystal violet, and the nitrogen mustards methyl bis ( $\beta$-chlorethyl) amine hydrochloride, $p$-di-(2-chlorethyl)amino-DL-phenylalanine, and $\beta$-chlorethylamine hydrochloride were tested in Escherichia coli 15, t- containing 5-bromouracil. These bacteria showed no hypersensitivity to any of the agents except for the latter compound, $\beta$-chlorethylamine; however, $E$. coli 15 wild-type demonstrated a similar sensitivity (maximum of ten-fold) when grown in 5-bromouracil before treatment with the mustard. Growth in 2-thiothymine, similarly, did not affect the sensitivity of $\boldsymbol{E}$. coli $15, \mathrm{t}^{-}$to any of these agents. 


\section{Effects of u.v. on E. coli containing 5-bromouracil}

\section{DISCUSSION}

The u.v.-sensitization effect by 5-bromouracil is proportional to the extent of incorporation of the analogue into DNA under defined conditions for a given medium. The incorporation of a given amount of 5-bromouracil into DNA in enriched medium results in a lower dose-increase effect than in minimal medium. This may be due, in part, to the contribution of the general inhibitory effect of the analogue in minimal medium to u.v. sensitization. For example, very high concentrations of 2-thiothymine, which is not incorporated, result in a slight increase in u.v. sensitization. Therefore, if u.v. sensitization is to be used as an index of incorporation, it must be done in a carefully calibrated system. On the basis of these findings (Greer \& Zamenhof, 1957) radiation sensitization has been used as an index of 5 -bromouracil incorporation in several systems including bacteriophage (Kozinski \& Szybalski, 1959; Litman $\&$ Pardee, to be published). Furthermore, sensitization by 5-bromodeoxyuridine has recently been demonstrated in human cells (Szybalski \& Djordjeric, 1959).

Because $48 \%$ incorporation of 5-bromouracil is obtained in conditions where there is an approximate $50 \%$ decrease in viability, it has been suggested that 5-bromouracil may be incorporated only in bacteria that become inviable. This appears unlikely in view of the present studies for it was necessary for the bacteria containing 5 -bromouracil to be viable in order to be killed by u.v. radiation.

In view of the findings of Dunn \& Smith (1955) that there is an increase in the content of 6-methylaminopurine in DNA under conditions of thymine starvation and growth in the presence of 2 -thiothymine, one may conclude that this alteration in DNA content does not affect the sensitivity of the bacteria to $u . v$. radiation. In addition, it may be assumed that the presence of an unnatural analogue (5-fluorouracil) in RNA does not affect the u.v. sensitivity of the bacteria used in these studies.

One may consider that the major effect of 5-bromouracil incorporation in these studies is to alter the function of the genetic material, not necessarily in a hereditary way; that is, to lead to some impairment of gene function without causing mutation. Thus far, 5-bromouracil incorporation per se has not been found to affect any specific physiological processes of the organisms (which are, of course, gene controlled) except by mutation (Zamenhof \& Griboff, 1954; Zamenhof, De Giovanni \& Greer, 1958; Litman \& Pardee, 1956, Benzer \& Freese, 1958). It is possible, then, to view the present findings (greater sensitization) as an instance wherein one can distinguish unimpaired genes from impaired ones, and as the first demonstration of a mass change in DNA resulting in a mass change in biological properties.

In the absence of all but suggestive evidence, one may speculate as to the mode of action of 5-bromouracil in leading to increased sensitivity to u.v. radiation. This mechanism may include the role played by the different u.v. absorption of 5-bromouracil than of thymine. This could be tested by use of monochromatic u.v. radiation. The findings of Moore \& Thomson (1956) that 
5-bromouracil is less stable to u.v. radiation than thymine or thymidylic acid are pertinent to these considerations. Also one might consider the possibility that replacement of a methyl by a bromine group may affect the local bond strength in DNA leading to a structure with less integrity to an inactivating agent. Not any inactivating agent, however, can show this effect as studies with peroxide and the mustards have indicated. Furthermore, the experiments utilizing heat indicate that the u.v.-sensitization effect may not be simply due to differences in u.v. absorption. The mechanism of the hypersensitivity of bacteria containing 5-bromouracil to heat is under investigation in studies on the depurination of DNA by heat. The speculation on the mechanism of u.v. sensitization will be subjected to further testing when 5-bromouracil-containing DNA that has biological (transforming) activity will be irradiated.

The fact that bacteria containing 5-bromouracil in their DNA are not photoreactivated as readily as normal bacteria may imply that the extra lethality is due in large part to direct or irreversible effects of u.v. radiation. Possibly consistent with this suggestion is the observation that $\mathrm{H}_{2} \mathrm{O}_{2}$ does not affect Escherichia coli $15, \mathrm{t}^{-}$containing 5-bromouracil differently than normal cells. When DNA containing 5-bromouracil is irradiated, the products of irradiation may undergo less repair than normal DNA in both light and dark reactions. Photochemical studies like those of Shih Yi Wang (1959) on the irradiation of pyrimidines at high doses of u.v. radiation may elucidate the mechanism of the present findings. DNA containing 5-bromouracil may not serve as a substrate for a photoreactivating enzyme as well as normal DNA. This hypothesis could be tested in vitro in a system in Haemophilus influenzae described by Goodgall, Rupert \& Herriott (1957).

The different pattern of u.v. sensitivity after growth in 5-bromouracil of two seemingly identical strains, Escherichia coli $15, \mathrm{t}^{+}$(a back mutant from wild-type) and $E$. coli 15, are consistent with the findings of Zamenhof $1958 a$ ) who showed that the back-mutant requires thymine at elevated temperatures, whereas the original wild-type does not. These results suggest that the nutritional independence of $E$. coli $15, \mathrm{t}^{+}$is achieved in an alternate way from the wild-type.

The possible ultimate practical application of a marked selective killing by radiation within a cell population where the basis of selection (level of incorporation of 5-bromouracil) depends on a modification of nucleic acid metabolism should be noted.

5-Bromouracil does not increase the frequency of u.v.-induced mutants at the thymine-dependent locus in Escherichia coli $15, \mathrm{t}^{-}$. These results are similar to the results of studies by Demerec \& Latarjet (1946), who found that induced mutagenesis is dose dependent rather than survival dependent in $\boldsymbol{E}$. coli $\mathbf{B}$ and $\mathbf{B} / \mathbf{R}$. If growth in 5-bromouracil prior to irradiation affects the subsequent expression of u.v.-induced mutants, for example, by interfering with the rate of either DNA, or protein synthesis and if the mutant clones obtained in the experiments summarized in Fig. 6 are not derived from zeropoint mutants (which is most likely) then the conclusions are to be reconsidered for there may be a higher induction coupled with a lower expression. It is 


\section{Effects of u.v. on E. coli containing 5- bromouracil}

possible that 5-bromouracil would more readily increase the frequency of u.v.-induced forward or auxotrophic mutation since its presence results in an inactivation phenomenon. This was not tested. A u.v.-dose increase effect may also take place at loci where 5 -bromouracil itself is mutagenic. In view of the findings of Benzer \& Freese (1958) in bacteriophage, there may be other loci that have not been investigated that would respond to u.v. radiation after 5-bromouracil incorporation in a manner differing from the thymine-dependent locus.

The author wishes to acknowledge the encouragement and interest of Dr S. Zamenhof throughout the course of this work. The technical assistance of Miss Lillian Blaschke in the final stages of this research is gratefully acknowledged. This work was supported by the Atomic Energy Commission, Grant No. AT (30-1)-1928 to Dr S. Zamenhof.

\section{REFERENCES}

BENZER, S. \& Freese, E. (1958). Induction of specific mutations with 5-bromouracil. Proc. nat. Acad. Sci., Wash. 44, 112.

Comen, S. S. \& Barner, H. D. (1954). Studies on unbalanced growth in Escherichia coli. Proc. nat. Acad. Sci., Wash. 40, 885.

Cohen, S. S., Flaks, J. G., Barner, H. D., Loeb, M. R. \& Lichtenstein, J. (1958). The mode of action of 5-flurouracil and its derivatives. Proc. nat. Acad. Sci., Wash. 44, 1004.

Demerec, M. \& LATARJet, R. (1946). Mutations in bacteria induced by radiations. Cold Spr. Harb. Symp. quant. Biol. $11,38$.

Dunn, D. B. \& Smith, J. D. (1955). Occurrence of a new base in the deoxynucleic acid of a strain of Bacterium coli. Nature, Lond. 175, 336.

Goodgall, S. H., Rupert, C. S. \& Herriott, R. M. (1957). Photoreactivation of Hemophilus influenzae transforming factor for streptomycin resistance by an extract of Escherichia coli B. In The Chemical Basis of Heredity, p. 341 (ed. W. D. McElroy \& B. Glass). Baltimore Md.: The Johns Hopkins Press.

Greer, S. \& Zamenhof, S. (1957). Effect of 5-bromouracil in deoxyribonucleic acid of $E$. coli on sensitivity to ultraviolet irradiation. Amer. chem. Soc. Abstr. (131st meeting), p. 3C.

Greer, S. \& Zamenhof, S. (1959). Loss of purines from DNA heated in mutagenic conditions at physiological pH. Fed. Proc. 18, 238.

KelNer, A. (1949). Photoreactivation of ultraviolet-irradiated Escherichia coli, with special reference to the dose-reduction principle and to ultraviolet-induced mutation. J. Bact. 58, 511.

Kozinski, A. W. \& SzYbalski, W. (1959). Dispersive transfer of the parental DNA molecule to the progeny of the phage $\phi X-174$. Virology, 9, 260.

Litman, R. M. \& Pardee, A. B. (1956). Production of bacteriophage mutants by a disturbance of deoxyribonucleic acid metabolism. Nature, Lond. 178, 529 .

Moore, A. M. \& Thomson, C. H. (1956). Photodecomposition of pyrimidine compounds. In Progress in Radiobiology, p. 75 (ed. J. S. Mitchell, B. E. Holmes \& C. L. Smith). Edinburgh: Oliver and Boyd.

Newcombe, H. R. (1952). A comparison of spontaneous and induced mutation of E. coli to streptomycin resistance and dependence. J. cell. comp. Physiol. 39, 13 (suppl. 1).

Ryan, F.J. \& Schneider, L. (1948). The consequences of mutation during the growth of biochemical mutants of Escherichia coli. J. Bact. 56, 699.

Szybalski, W. \& DJordjeric, B. (1959). Radiation sensitivity of chemically modified human cells. Rec. Genet. Soc. Amer. 28, 100. 
WANG, S. Y. (1959). Ultraviolet irradiation of 1,3-dimethylthymine. Nature, Lond. 184, B.A. 59.

WITKIN, E. M. (1947). Genetics of resistance to radiation in E. coli. Genetics, 32, 221.

ZAMENHOF, S. (1956). Biology and biophysical properties of transforming principles. Progr. Biophys. 6, 85.

Zamenhof, S. (1957). Properties of the transforming principles. In The Chemical Basis of Heredity, p. 351 (ed. W. D. McElroy \& B. Glass). Baltimore, Md.: The Johns Hopkins Press.

Zamenhof, S. (1958a). Nucleic acid synthesis in back-mutants of Escherichia coli. Abstr. Pap. Amer. Chem. Soc. (133rd meeting), p. 9C.

ZamenhoF, S. $(\mathbf{1 9 5 8 b})$. Some studies on the correlation between the change in structure and the change in function of deoxyribonucleic acids. In Recent Progress in Microbiology, Symposia, VIIth Int. congr. Microbiol. p. 139.

Zamenhof, S., De Giovann, R. \& Rich, K. (1956). Escherichia coli containing unnatural pyrimidines in its deoxynucleic acid. J. Bact. 71, 60.

Zamenhof, S., De Grovanni, R. \& Greer, S. (1958). Induced gene unstabilization. Nature, Lond. 181, 827.

Zamenhor, S. \& Greer, S. (1958). Heat as an agent producing high frequency of mutations and unstable genes in Escherichia coli. Nature, Lond. 182, 611.

ZAMENhoF, S. \& GRIBOFF, G. (1954). Incorporation of halogenated pyrimidines into the deoxyribonucleic acids of Bacterium coli. Nature, Lond. 174, 306.

Zamenhof, S., Reiner, B., De Grovanni, E. \& Rich, K. (1956). Introduction of unnatural pyrimidines into deoxyribonucleic acid of Escherichia coli. J. biol. Chem. 219, 165.

Zamenhof, S., Rrch, K. \& De Giovanni, R. (1958). Further studies on the introduction of pyrimidines into deoxyribonucleic acids of Escherichia coli. J. biol. Chem. 232, 651 .

Zamenhof, S., Rich, K. \& De Grovanni, R. (1959). Studies on thymine 5-bromouracil 'exchange' in deoxynucleic acids in Escherichia coli. J. biol. Chem. 234, 2960. 